\title{
Comunidade À mesa: a comensalidade em O Pai Goriot de Balzac
}

\author{
Rebekka Fernandes DANTAS* \\ Alexsandro Galeno Araujo DANTAS**
}

\begin{abstract}
RESUMO: Nosso objetivo é compreender a comensalidade como um fenômeno da sociedade, que se modifica no mundo contemporâneo, a partir da obra O pai Goriot, de Balzac. A história se passa em uma pensão de um bairro decadente de Paris, chamada Casa Vauquer. Nesse ambiente, a mesa aparece como palco de práticas alimentares, bem como de desentendimentos e desarmonias na vida em grupo ou em comunidade. Que comunidade é essa? Para pensá-la utilizaremos as noções de comunidade inconfessável e inoperante de Maurice Blanchot e Jean-Luc Nancy. Essas comunidades não são possíveis na comunhão, mas sim no estranhamento. Com essa base pensamos na mesa da Casa Vauquer como um espaço de hostilidade e hospitalidade, que apresenta marcas do individual e do coletivo e onde prevalecem conflitos e desordens.
\end{abstract}

PALAVRAS-CHAVE: Comunidade. Comensalidade. Balzac. O pai Goriot.

\section{Introdução}

Há 500 mil anos o homem aprendeu a dominar o fogo e com ele surgiu a cozinha, fenômeno civilizatório que se acreditava ser elemento de distinção

\footnotetext{
UFRN - Universidade Federal do Rio Grande do Norte. Centro de Ciências Humanas, Letras e Artes. Programa de Pós-Graduação em Ciências Sociais. Natal - RN - Brasil. 59078-970 - rebekkafernandes@ hotmail.com

** UFRN - Universidade Federal do Rio Grande do Norte. Centro de Ciências Humanas, Letras e Artes. Programa de Pós-Graduação em Ciências Sociais. Natal - RN - Brasil. 59078-970 - alexgalenno@ gmail.com
} 
entre homens e animais. Passou-se a acreditar que o comportamento do homem se diferenciava do dos animais pela comensalidade, simplesmente definida como o ato de comer e beber junto. Comensal deriva do latim commensalis (de cum, com + mensa, mesa) (HOUAISS, 2009) e significa "conviver à mesa". No entanto, ainda que os animais não façam refeições à mesa, a comensalidade é também uma atividade realizada por eles. Temos como exemplo os felinos, que estabelecem estratégias de caça pelos machos e levam a presa para o bando que a partilham (LANDINI, 1998).

O que nos diferenciaria então? O modo como fazemos a nossa cozinha e a nossa mesa. A alimentação, além de ser uma ação que partilhamos com os animais, é algo que nos distingue deles (PERLÉS, 1979) pela criação de normas, de mitos, pela escolha minuciosa dos ingredientes, pelos diferentes modos de cocção que descobrimos e ensinamos e pela função civilizadora que damos às refeições, longe de serem utilizadas unicamente para matarmos a fome.

As regras que marcam esse processo civilizador não são as mesmas para as sociedades, de modo que as pessoas de unidades sociais diferentes se comportam de forma diferente e em maneiras muito específicas, e é por isso que achamos estranhos os hábitos alimentares do homem da Idade Média, como o de limpar o nariz com a mão, desde que não o assoasse na toalha da mesa (ELIAS, 1994b).

Diz-se que para ser aceito em uma mesa é necessário saber comportar-se como os demais para, então, ser considerado parte de um grupo ou de uma comunidade. A família, o monastério, o symposium, o convivium reafirmam à mesa uma ideia de pertencimento e identidade, apesar de que comer junto não significa necessariamente estar em perfeita harmonia, uma vez que "se a mesa é a metáfora da vida, ela representa de modo direto e preciso não apenas o pertencimento a um grupo, mas também as relações que se definem nesse grupo" (MONTANARI, 2008, p. 160).

Refeições cotidianas, almoços de domingos, comemorações de aniversários, refeições para tratar de negócios, confraternizações natalinas etc. fazem parte da nossa rotina ainda hoje. Porém, ainda que essa prática não esteja desaparecida, percebemos um individualismo da alimentação que acompanha as transformações da sociedade.

Sloterdijk (2009, p. 450) aponta para o espaço de individualismo do apartamento, onde o comensal desempenha duas funções diferentes: "quem se abasta da própria cozinha desempenha eo ipso o duplo papel de anfitrião e convidado, de cozinheiro e comensal".

Em oposição ao individualismo, mas também a uma ideia de comunhão, harmonia e coesão, Jean-Luc Nancy (2000) e Maurice Blanchot (2013) pensam uma comunidade de estranhamento e desarmonia que guiará as nossas ideias para pensar a comensalidade, comunidade formada à mesa. 
Nancy (2000) considera que a comunidade é inoperante. Não como se ela estivesse perdida ou limitada a comunidades tradicionais, pois para ele, a comunidade perdida é um fantasma. Dialogando com esse filósofo, Blanchot (2013, p. 60) discute essa ideia, expondo que a comunidade perdida só é provável na impossibilidade da sua existência. Mesmo a comunidade dos amantes não almeja a fusão, mas funda-se mais na estranheza que na proximidade. "Paradigma do amor compartilhado, exclui tanto a simples mutualidade quanto a unidade em que o Outro se fundiria no Mesmo".

Do mesmo modo, apesar de a comensalidade apresentar uma forte dimensão social que implica na presença de um grupo ou de uma comunidade, não necessariamente ocorre em uma atmosfera de comunhão, ou de partilha e bem-estar. Como percebemos à mesa da pensão Vauquer em O pai Goriot (BALZAC, 2012), comer junto torna-se momento de desavenças e conflitos, onde, mais do que unir os iguais, coloca os diferentes em convívio.

Assim, guiados pelas ideias apresentadas, temos o objetivo de compreender o ato de comer e beber juntos no romance O pai Goriot, de Balzac (2012). Realizamos uma primeira leitura do romance e em seguida transcrevemos todos os momentos em que havia alguma referência à alimentação. Parte dessas referências caracterizava os espaços da obra e os personagens, contribuindo para descrever as suas singularidades e compreender o romance. Outra parte das referências estava presente ao longo das treze cenas que se passam à mesa, investigadas por análise temática, proposta por Mayring (1983) e que consiste em um procedimento gradual de redução do texto qualitativo em séries de paráfrases. A partir daí, identificamos temas que caracterizam a comensalidade na Casa Vauquer.

Com isso foi possível discutir três temas que dizem respeito à comensalidade que acontece na pensão Vauquer: é um espaço de hostilidade e de hospitalidade; apresenta marcas do individual e do coletivo; nela prevalece a desordem. No entanto, antes de passarmos à discussão desses temas faremos uma reflexão sobre a relação entre alimentação e literatura, tentando responder à seguinte pergunta: Por que, a partir da literatura de Honoré de Balzac, podemos pensar a alimentação e fazer Ciência?

\section{A alimentação na literatura de Balzac}

A alimentação e as letras estão relacionadas de tal maneira que Cadmo, herói que trouxe a escrita para a Grécia, foi o cozinheiro do rei de Sidon, além do fato de que tanto a linguagem quanto a gastronomia utilizam o mesmo órgão, a língua (BARTHES, 1988). 
Desde a Antiguidade a literatura narra as refeições como forma de alimentar o prazer, é bem verdade que desde então também a literatura expressa momentos de comensalidade, permitindo-nos conhecer e compreender esse rito.

Em O Pai Goriot, (BALZAC, 2012) diversas referências são feitas à alimentação, incluindo alimentos, utensílios, hábitos, práticas alimentares e modos à mesa. A sala de refeições é recorrente, e os almoços e jantares participam do desenrolar da história, estando presente em treze momentos ao longo das mais de 300 páginas, o que configura a obra como um campo de pesquisa farto para o estudo da comensalidade. O comer é um aspecto marcante da literatura de Balzac. Para ele, "nada evoca melhor a atmosfera de uma casa ou a característica de um protagonista que a descrição de sua mesa" (MUHLSTEIN, 2010, p. 9, tradução nossa).

O protagonista deste romance, na sua simplicidade, tinha como jantar predileto a sopa, o cozido e um prato de legumes, comido com pão que ele, como fabricante de massas que fora, cheirava para identificar a qualidade da farinha. Sua felicidade era poder tomar o café numa tigelinha cuja tampa tinha duas pombas beijando-se, presente de sua falecida esposa. Há dias em que sofre tanto por amor às filhas que mal come, mas anima-se com o jantar encomendado pela sua filha no Café des Anglais.

Léon Gozlan (1863, p. I-II, tradução nossa), amigo e secretário de Balzac e autor de algumas de suas biografias, define-o pela palavra composta alemã tischreden, (mesa e conversa). Em português, poderíamos traduzir para conversas à mesa, "cotovelos sobre a mesa, risos, a boca plena, encantadores vinhos sensíveis, abandono adorável do coração seguindo o estômago, poesia da digestão, discussões a facas maçantes".

Convidava frequentemente os amigos para verdadeiros banquetes, ainda que não tivesse dinheiro para pagar o aluguel da casa. Presunto cozido, tarambolas gratinadas, vitela recheada, filés de esturjão, aspargos brancos, abacaxi empanado, costeletas, ostras, são pratos que compunham os jantares requintados que Balzac habitualmente realizava aos sábados (MONTEILHET, 2011).

No entanto, mesmo Balzac, conhecido pelo seu estilo glutão e o exagerado pedido: "Garçon, un cent d'hûitres" (MUHLSTEIN, 2010), longe de ser insaciável, tinha longos momentos de moderação. Alternava a comilança com períodos de esforço, contentando-se com refeições rápidas, correspondentes aos momentos em que escrevia, trabalhando por horas a fio noite adentro, bebendo grandes quantidades de café forte.

Balzac (2009) discorre sobre o café em seu texto Tratado dos Excitantes Modernos, que serviu, inicialmente, como prefácio à segunda edição de $A$ fisiologia do Gosto, escrita pelo cozinheiro Brillat-Savarin (1995). Ambos viveram o século XIX, época caracterizada por uma viagem positivista e romântica, mas também 
por um mal de viver (BARTHES, 1988). É nesse século que surge o realismo na França, contrapondo-se ao idealismo romântico e ligando-se às correntes filosóficas da época, como o positivismo.

O positivismo que tem como grande expoente Auguste Comte, lembrado pela definição dos fatos sociológicos e por uma compulsão pela sistematização que correspondia à forma como moldava a própria vida (LEPENIES, 1996). Entusiasma as ideias de Émile Durkheim (2007) e o seu método, definindo-o na obra clássica As regras do método sociológico, em que, já no prefácio, defende o racionalismo científico e a separação entre sociologia e psicologia. A primeira regra que propõe é considerar os fatos sociais como coisas, do mesmo modo como os cientistas naturais tratam os seus objetos de pesquisa.

Lepenies (1996, p. 14) explica que até o século XVIII não existia uma separação nítida entre a produção da obra literária e da científica. O conde de Buffon, naturalista e escritor francês, por exemplo, escreve a sua Historie naturelle, que é um sucesso de vendas. Após cem anos da publicação de sua obra, Balzac refere-se a ele como "um homem da ciência natural que por fim foi rejeitado por sua corporação como literato", e que, como grand seigneur da ciência, sabia tirar proveito de sua atividade.

Se por um lado a ciência exerceu influência na literatura, sobretudo em "A Comédia Humana", por outro, a sociologia positivista expulsa todo e qualquer saber que não seja científico, trazendo consequências para a forma de pensar dos tempos modernos.

A sociedade percebia a importância da literatura para pensar a ciência. Instruía ao mesmo tempo em que divertia. Porém, após essa época, aquelas obras com caráter tanto literário quanto científico, passam a ser consideradas para leigos e mulheres e ocorre uma ruptura entre literatura e ciência. A reforma da Universidade de Sorbonne exemplifica bem isto. Influenciada por Émile Durkheim, a ciência só teria valor se servisse às profissões econômicas, e a literatura acaba por perder terreno no campo científico (LEPENIES, 1996).

Assim, a emergência do positivismo contribui para gerar um paradigma científico que supervaloriza as ciências naturais e exclui saberes como, as artes, que apesar de distintas da ciência, também constitui uma forma de compreender o homem.

A literatura, por exemplo, pode ser interessante para pensar ciência porque ambas são discursos, mesmo que as suas linguagens não sejam professadas da mesma maneira. As características de realidade e irrealidade da literatura permitem que todas as ciências estejam presentes na literatura: "faz girar os saberes, não fixa, não fetichiza nenhum deles; ela lhes dá um lugar indireto, e esse indireto é precioso. A literatura é o mal, ainda que não contrário ao bem, que decorre da possibilidade de 
infringir a regra" (BARTHES, 1988, p. 24), ela angustia e desordena, permitindo-nos pensar uma ciência que foge à rigidez, diferentemente da ciência que segue regras, como aquelas definidas por Durkheim em seu método.

\section{Hostilidade e hospitalidade}

Estamos em Paris no ano de 1819 e chegamos à parte baixa da rue Neuve-Sainte-Geneviève, hoje rue Turnefort, entre o Quartier Latin e o Fauborg Saint-Marceau, um ponto em que o terreno se inclina para a rue de l'Arbalète de forma tão íngreme que nem mesmo os cavalos a sobem ou a descem, resultando em um silêncio que reina nos arredores. [...]

Chegamos a uma pensão com fachada de cor amarela e uma portinha encimada por uma tabuleta, em que se lê: "CASA VAUQUER. Pensão burguesa para os dois sexos e outros" (BALZAC, 2012, p. 28).

A tabuleta da propriedade da Sra. Vauquer, sugere receber qualquer desconhecido que se disponha a atravessar a alameda orlada de gerânios, lourosrosa e romãzeiras. Era uma pensão que abrigava estudantes, foragidos das galés, aposentados e deserdados em busca de abrigo.

A Sra. Vauquer se pergunta: "Onde teriam aqueles infelizes encontrado, em Paris, pelo preço que ela cobrava, alimentos sãos, abundantes e um quarto que eles tinham o direito de tornar, se não elegante ou cômodo, pelo menos limpo e salubre?" (BALZAC, 2012, p. 42).

A relação entre os hóspedes e o hospedeiro é sempre ambígua. Curiosamente, a palavra hóspede vem do latim hospes (hóspede) ou hostis (inimigo, estrangeiro) (HOUAISS, 2009), corroborando com o temor sempre existente diante do estrangeiro, do desconhecido, do outro (DERRIDA; DUFOURMANTELLE, 2003). Existe uma relação de interdependência entre, por exemplo, a Sra. Vauquer - que oferece abrigo e alimentação a preço baixo - e os seus pensionistas, sem os quais ela está falida. Ao final do romance, a Casa é praticamente esvaziada e a proprietária se desespera: 
— Amanhã de manhã só precisa fazer três taças de café, Sílvia! Imagina! Minha casa vazia! Não é de cortar o coração? Que será a vida sem meus pensionistas? Absolutamente nada. Aí está minha casa desmobilizada de seus homens. A vida está toda nos móveis. Que fiz eu para merecer todos esses desastres? Nossas provisões de feijão e batatas foram feitas para vinte pessoas. A polícia em minha casa! Vamos passar a comer somente batatas! E terei de despedir Cristóvão! (BALZAC, 2012, p. 252).

A hospitalidade, ainda que ligada a uma acolhida cortês e afável, nunca é cômoda nem espontânea. Aquele que procura uma morada não sabe se será bem recebido, e aquele que recebe sempre se pergunta se o hóspede é um vagabundo desamparado, uma pessoa de boas intenções ou se terá dinheiro para pagar o aluguel (MONTANDON, 2011), preocupação constante da Sra. Vauquer.

Jacques Derrida e Anne Dufourmantelle (2003), propõem a hospitalidade incondicional como uma forma de lidarmos com o outro. No entanto, em oposição a essa hospitalidade ritual foram instituídos locais de acolhimento, como hospitais e hospícios, refúgios oferecidos no século XIX aos indigentes (GUILLAUME, 2011) como forma de acolhê-los, mas também de separá-los e excluí-los, protegendo os outros das doenças morais e físicas (FOUCAULT, 1984). Com eles também vieram as hospedarias: albergues, alojamentos e pensões. Esses locais instauram o pagamento em troca de abrigo e alimentação (GRASSI, 2011), fazendo desvanecer a ideia de uma hospitalidade gratuita.

O pai Goriot casou suas filhas - Anastácia e Delfina - a primeira com o conde de Restaud e a última, com o banqueiro e barão de Nucingen. Os genros e as filhas sentem-se chocados e envergonhados ao verem o Sr. Goriot continuar na vida comercial e por isso ele a deixa e resolve morar na pensão Vauquer. Ao chegar nesse estabelecimento, o pai Goriot era um ancião de cerca de 69 anos. Ocupou um dos melhores quartos e pagava mil e duzentos francos, vestindo-se com um traje azul-claro e um colete de piquê branco, mas aos poucos é arruinado pelas filhas e passa a viver no pior quarto da pensão. Seus alimentos preferidos? Pão, sopa e um prato de legumes. Esses alimentos são ricos em carboidratos e carentes em proteínas, principal nutriente das carnes, lembrando os hábitos alimentares dos monges da Idade Média, que, como já dito anteriormente, formavam uma comunidade, à mesa, de pertencimento.

Enquanto os monges se abstêm em prol de uma questão religiosa, o pai Goriot se dispõe a sacrifícios pelas filhas: “Ora, comerei somente pão!” (BALZAC, 2012, p. 283). E afirma, no auge de seu delírio, que voltará ao comércio e comprará cereais em Odessa, onde o trigo custa três vezes menos. O lucro destinará às filhas, que arruinaram a si mesmas e ao próprio pai. O simples fato de tocarem no nome delas 
provoca no velho um estado meditativo que o faz comer maquinalmente. É sem dúvidas um personagem estranho. Se inicialmente é bem recebido e aceito à mesa da Sra. Vauquer, ao longo dos acontecimentos do romance acaba hostilizado e alvo de chacotas, permitindo-nos pensar a relação ambivalente que temos com o Outro: hospitaleira ou hostil.

A Sra. Vauquer media com precisão os cuidados dispensados aos pensionistas de acordo com a mensalidade que pagavam e, com a presença do pai Goriot, passou a esforçar-se em dar à casa certo decoro. "Passou a cuidar da mesa, acendeu o fogo nas salas durante quase seis meses e cumpriu as promessas dos prospectos tão bem que até fez despesas" (BALZAC, 2012, p. 46). No entanto, um episódio transformou o tratamento despendido pela Sra. Vauquer.

No mesmo período em que o pai Goriot chega à pensão, instala-se lá a Sra. d'Ambermesnil, uma mulher acima dos trinta anos que esperava a regularização de uma pensão que lhe era devida por ser viúva de um general. "As duas viúvas, após o jantar, subiam juntas ao quarto da Sra. Vauquer e lá ficavam a tagarelar bebendo cassis e comendo gulodices, reservadas à boca da dona da casa" (BALZAC, 2012, p. 46), bem como planejando as investidas ao Sr. Goriot. Porém, Sra. d'Ambermesnil também se interessou pelo fabricante de massas e, em vez de elogiar a dona da pensão para ele, assediou o velho, que foi refratário às suas tentativas. Desgostosa, parte da pensão sem pagar seis meses de aluguel. O que faz a proprietária? Acostumada a responsabilizar os outros por seus infortúnios, considera o Sr. Goriot como a causa de seu prejuízo e influencia todos os outros moradores a compartilharem da mesma antipatia. Ela começa por suprimir as coisas supérfluas que introduzira na pensão: "Basta de pepinos e de anchovas! Isso é bobagem! - Disse a Sílvia, no dia em que restabeleceu o programa" (BALZAC, 2012, p. 49).

Nos momentos das refeições, todos os pensionistas desconfiam desse homem e não acreditam que as duas moças bem vestidas que o visitam algumas vezes fossem suas filhas. Durante um jantar, a Sra. Vauquer põe em dúvida a sua paternidade. Com ar de troça pergunta: "Então, suas filhas não vêm visitá-lo?" O pai Goriot responde que vêm às vezes e todos passam a criar hipóteses sobre o velho: é um libertino que se arruinou por mulheres (BALZAC, 2012, p. 54). É motivo de zombaria: o pobre velho, aturdido com um falatório à mesa, ficou momentaneamente imóvel. "Cristóvão retirou o prato do bom homem, pensando que ele tivesse terminado a sopa e quando o pai Goriot, depois de ter arrancado o chapéu, baixou a colher, bateu com ela na mesa. Todos soltaram uma gargalhada" (BALZAC, 2012, p. 79).

Em contraposição à hospitalidade que lhe é assistida quando chega à Casa Vauquer, servem-lhe leite bebido por um gato. Cristóvão, o criado, mandado por Sílvia, responsabiliza-se por olhar o leite. No entanto, quando a Sra. Vauquer desce, o gato Mistigris acabara de derrubar com uma patada um prato que cobria 
uma tigela, da qual ele bebia apressadamente. Sílvia encontra uma solução: "Não se preocupe, patroa. Vou fazer com este leite o café do pai Goriot. Vou pôr mais água e ele nem notará. Ele não presta atenção em nada, nem mesmo no que come" (BALZAC, 2012, p. 66).

Não percebemos, portanto, nesses momentos de comensalidade da pensão Vauquer a visão idílica da comunhão, frequentemente vista como uma reunião de iguais, como nos mostra Montanari (2008):

Em todos os níveis sociais, a participação na mesa comum é o principal sinal de pertencimento ao grupo. Esse pode ser a família, mas também uma comunidade mais ampla: toda confraria, corporação, associação reafirma à mesa a própria identidade coletiva; toda comunidade monástica se reconhece no refeitório, onde todos são obrigados a dividir a refeição (e somente os "excomungados", aqueles que se mancharam com alguma culpa, são excluídos temporariamente). (MONTANARI, 2008, p. 159).

É uma comensalidade que se forma em uma comunidade como a que nos mostra Nancy (2000), distante do paradigma da família, da cidade ateniense, da república romana, das corporações e das fraternidades, sempre referências a idades perdidas no passado, em que a comunidade se tecia com vínculos estreitos, harmoniosos e irrompíveis, ou como Blanchot (2013, p.16-17), em sua obra A comunidade inconfessável que tem a ideia de que a comunidade não almeja a fusão, mas funda-se mais na estranheza que na proximidade, pois o homem "não busca se associar a um outro ser para formar uma substância de integridade. A consciência da insuficiência vem da sua própria colocação em questão, a qual tem necessidade do outro ou de um outro para ser efetuada".

A comunidade que esses autores propõem não se funda na ideia de identidade, que corriqueiramente nos aparece com uma ideia de pureza e tradição imutável, desconsiderando as constantes trocas e adaptações, mas sim na de alteridade, de modo que o outro, em enfrentamento com outros, promove uma outra coisa.

\section{Marcas de coletividade e de individualismo na mesa da Casa Vauquer}

A liberdade associa-se à ideia de individualidade e a segurança, à de coletividade. Na verdade, o individual e o coletivo, o indivíduo e a sociedade, a liberdade e a segurança não são antinomias: os indivíduos formam a sociedade, assim como a sociedade é uma sociedade de indivíduos. O ser humano singular é sempre gerado por outros seres humanos, pois todo homem nasce de um grupo de pessoas já 
existentes antes dele. "Numa palavra, cada pessoa que passa por outra, como estranhos aparentemente desvinculados na rua, está ligada a outras por laços invisíveis, sejam estes laços de trabalho e propriedade, sejam de instintos e afetos" (ELIAS, 1994a, p. 22).

Simmel (2004) chama a atenção para as dimensões individual e coletiva que perpassam o comer:

De tudo o que os seres humanos têm em comum, o mais comum é que precisam comer e beber. E é singular que este seja o elemento mais egoísta, que é por sinal o mais imprescindível e imediatamente restrito ao indivíduo. Já o que se pensa, pode-se dar a conhecer a outros; o que se vê, pode-se deixar que outros vejam; o que se fala, centenas podem escutar; mas o que se come não pode, de modo algum, ser igualmente comido por outro. Em nenhuma esfera elevada da vida humana pode-se encontrar uma tal situação: de que o que um deva possuir seja absolutamente impossível para o outro. (SIMMEL, 2004, p. 160).

Para ele, aliamos o estar junto à exclusividade fisiológica de nutrirmo-nos. Não comemos nem bebemos do mesmo e sim de porções exclusivas de alimentos e bebidas. O prato no qual servimos a refeição é uma criação individualista e indica que aquela porção de comida é para uma única pessoa. Isso é demarcado inclusive pela linha circular desse utensílio, diferentemente da gamela, usada em épocas primitivas, de formato oval ou contendo cantos. Por outro lado, os pratos também estabelecem um compartilhamento, devendo ser iguais para todos os comensais, assim como os copos. Ao redor da refeição surgem prescrições quanto à forma de consumação. Por exemplo, enquanto alguns povos antigos comiam anarquicamente, quando tinham fome, outros seguiam uma regularidade nas refeições, permitindo que um círculo de pessoas se encontre em horários predeterminados.

Também podemos pensar em que situações comemos juntos. Onde? A que horas? Quem cozinha? O que se come em determinados momentos? Por que nos reunimos? Que relações acontecem no momento das refeições?

Percebemos na Casa Vauquer a presença de marcas da coletividade: espaços, horários, regras alimentares etc. e de individualidade: hábitos dos personagens que não agem em prol da harmonia e de comer juntos ou em comunidade. Inicialmente, serão apresentadas essas dimensões para entendermos e caracterizarmos as refeições que acontecem na pensão e para dar subsídios à compreensão das comunidades inoperante e inconfessável, opostas ao comunismo que é a coletividade em excesso e em comunhão, bem como à mera justaposição individualista, sobre a qual temos uma visão contratual. 
Às sete horas da manhã, o gato da Sra. Vauquer surge na sala de refeições precedendo sua dona e salta sobre o armário, farejando o leite contido em várias tigelas. Na Casa Vauquer, apesar da existência dos dois cômodos, a sala de refeições tinha duplo papel, e quase todas as noites os pensionistas a deixavam de acordo com o grau de interesse que a palestra lhe causava ou segundo a preguiça decorrente da digestão.

Por volta das nove horas e quinze minutos, Sílvia está aprontando o almoço, que geralmente sai às dez horas, como gosta a patroa. Nesse momento, alguns pensionistas descem atraídos pelo cheiro do refogado que está sendo preparado para aproveitar os restos de um carneiro. "Justamente quando os sete convivas tomaram lugar à mesa dando os bons-dias, soaram dez horas: ouviram-se na rua os passos do estudante" (BALZAC, 2012, p. 69). Pela manhã, além da Sra. Vauquer, sentavam-se à mesa os sete pensionistas internos: o pai Goriot, Eugênio de Rastignac, Vautrin, Srta. Michonneau, Poiret, Vitorina e a Sra. Couture. Mas também havia estudantes de direito ou medicina, e dois ou três fregueses que moravam no bairro, que ali apenas jantavam. É no almoço que a Casa Vauquer se apresentava como um espaço doméstico. Para aqueles sete pensionistas, a Casa Vauquer era sua casa.

A sala continha, ao jantar, dezoito pessoas e podia admitir vinte; pela manhã, porém, só apareciam os sete locatários, cuja reunião oferecia, durante o almoço, o aspecto de uma refeição em família. Desciam de chinelos, permitiam-se observações confidenciais a propósito das roupas ou da expressão dos externos e sobre os acontecimentos da tarde precedente, exprimindo-se com a confiança da intimidade (BALZAC, 2012, p. 35).

Para o jantar, agregavam Bianchon, interno no Hospital dos Capuchinhos, o pintor e o empregado do museu, que pagavam trinta francos por mês. Bem mais interessados em matar a fome do que em socializar-se com os demais, comiam uma refeição relacionada à situação do trabalho e não do cotidiano doméstico como pela manhã. É no jantar que a pensão abre as portas ao público, como os restaurantes, frequentados por qualquer um que tivesse dinheiro suficiente para usufruir de uma refeição.

Corbeau (1992) classifica as refeições em ordinárias e extraordinárias. A maioria das refeições realizadas na Casa Vauquer é ordinária e está relacionada aos tempos de trabalho que acabam por substituir a alimentação ordinária no seio familiar. É um momento para matar a fome e recarregar as energias gastas no serviço. No entanto, esse momento também poderia transformar-se em sociabilidade. 


\section{Rebekka Fernandes Dantas e Alexsandro Galeno Araujo Dantas}

Alguns pensionistas ainda estavam à mesa, comendo nozes, enquanto outros passeavam de um lado para o outro, continuando discussões iniciadas. (...). No inverno, era raro que a sala de jantar se esvaziasse inteiramente antes das oito horas, momento em que as quatro mulheres ficavam sós e se vingavam do silêncio que seu sexo the impunha naquela reunião masculina (BALZAC, 2012, p. 188).

Além de ser também palco de refeições festivas, como a comemoração promovida por Vautrin, um foragido que arquiteta um plano para matar o Sr. Taillefer, pai de Vitorina, e, dessa forma, fazer com que a jovem tivesse uma fortuna e se casasse com Eugênio. Ele resolve comemorar às vésperas do acontecimento com vinho de Bordéus. Ordena a Cristóvão que traga as garrafas, serve-se de algumas gotas e, sentindo um gosto estranho, dá a garrafa para Cristóvão, Eugênio e o pai Goriot.

Um traço do caráter de Vautrin "era pagar generosamente quinze francos pelo ponche de café e aguardente que tomava à sobremesa" (BALZAC, 2012, p. 40-41). A Srta. Michonneau, na iminência de ser expulsa da casa por desmascarar Vautrin, lembra: "Mas a minha pensão está paga, estou aqui graças ao meu dinheiro, como todos os outros - disse ela, lançando um olhar de víbora sobre os pensionistas" (BALZAC, 2012, p. 50). Diferentemente dos salões, aos quais só podiam ir convidados, as casas de pensão, como também os restaurantes, eram espaços que aceitam qualquer pessoa que possa pagar pelo serviço do estabelecimento.

Outros, como Vitorina, sentavam-se à mesa, esse espaço de sociabilidade e coletividade, mas não comiam, como os demais, expressando uma liberdade, mas também uma coletividade, uma vez que participavam do convívio. "Realmente comentou Bianchon, que estava junto de Rastignac. - A senhorita podia intentar um processo reclamando alimentos, pois não come. Oh! Reparem como o pai Goriot olha para a srta. Vitorina" (BALZAC, 2012, p. 70).

Para o jantar, simplicidade: sopa, pão e um prato de legumes, alimentos preferidos do pai Goriot. Para os almoços ordinários a Sra. Vauquer ordena à cozinheira Sílvia: "Alcança-me a camisola e vai tratar do almoço. Prepara o resto do carneiro com batatas e serve peras cozidas, dessas que custam meio soldo cada uma" (BALZAC, 2012, p. 65).

As situações são diversas e dentro delas podemos encontrar singularidades entre os comensais, bem como a liberdade que permite aos personagens recusar determinadas condutas. Ainda que se reúnam à mesa para almoçar e jantar, eles têm direito de expressar suas singularidades.

Em oposição a esses momentos de refeições compartilhadas, seja no cotidiano doméstico, na alimentação ligada ao trabalho ou à festa, os pensionistas podem ter seus próprios utensílios, ausentarem-se e usufruir de almoços e jantares com outras pessoas ou até mesmo sentarem-se à mesa e não comer. 
O pai Goriot, por exemplo, trazia seus próprios utensílios, diferentes dos demais: conchas, colheres de servir, talheres, galhateiros, molheiras, pratos, aparelhos de chá e uma tigelinha que apresentava duas pombas beijando-se:

é o primeiro presente que minha mulher me deu, no dia de nosso aniversário. Pobrezinha! Guardou suas economias de solteira para comprá-la. Veja, eu preferiria cavar a terra com as unhas a separar-me disto. Graças a Deus! Poderei tomar meu café nesta tigela todas as manhãs, durante o resto dos meus dias. Não tenho de que me queixar, estou com meu pão garantido por muito tempo (BALZAC, 2012, p. 44).

Outro traço de individualismo era não existir a obrigação de almoçarem todos juntos. "Goriot frequentemente jantara fora uma ou duas vezes por semana. Aos poucos, porém, esses jantares foram se espaçando, até não passarem de dois por mês" (BALZAC, 2012, p. 50). Essas ausências do Sr. Goriot convinham muito aos interesses da avarenta Sra. Vauquer, de modo que a progressiva pontualidade com que seu pensionista voltou a fazer as refeições na pensão a desagradou.

Rastignac também preferia o luxo nos grandes salões e frequentemente recebia convites íntimos para a casa da prima ou da amante. Assim, quando aparecia na pensão no horário das refeições, era recebido com ironia: "Muito bem! Sr. Eugênio disse Sílvia -, hoje o senhor vai almoçar com os outros" (BALZAC, 2012, p. 70).

Comer junto, portanto, não implica, necessariamente, uma relação de coletividade em que necessitamos suprimir nossos hábitos e vontades em prol da harmonia e coesão do grupo. No entanto, para estarmos juntos, algumas regras podem ser necessárias para que se promova a reunião, sem que para isso desconsideremos o diferente.

\section{Conflito e desordem}

Percebemos duas questões relacionados à desordem na Casa Vauquer. A primeira diz respeito ao ambiente em que as refeições são realizadas e o segundo à fragilidade das regras de etiqueta, parte do processo civilizador.

O ambiente em que as refeições são realizadas é miserável e sujo: "Reina ali, enfim, a miséria sem poesia; uma miséria econômica, concentrada, gasta, que não tem ainda lodo, mas manchas; que não tem buracos nem andrajos, mas uma podridão envelhecida" (BALZAC, 2012, p. 32). Se tomarmos a ideia de higiene de Mary Douglas (1990), poderemos considerá-lo em estado de desordem, que não se limita ao espaço, mas também atinge as relações, sempre desarmônicas, entre os personagens. Para essa autora 


\section{Rebekka Fernandes Dantas e Alexsandro Galeno Araujo Dantas}

a impureza é essencialmente desordem. A impureza absoluta só existe aos olhos do observador. Se nos esquivamos dela, não é por causa de um medo cobarde nem de um receio ou de um terror sagrado que sintamos. As ideias que temos da doença também não dão conta da variedade das nossas reações de purificação ou de evitamento da impureza. A impureza é uma ofensa contra a ordem. Eliminando-a, não fazemos um gesto negativo; pelo contrário, esforçamo-nos positivamente por organizar o nosso meio (DOUGLAS, 1990, p. 6-7).

Mesmo Douglas (1990), que acreditava tolerar bem a desordem, lembra-se do quanto se sentiu tensa num quarto de banho que, apesar de livre de impurezas, fora improvisado numa velha casa e o lugar tinha um sentido perdido com a sua transformação em quarto de banho.

Sujeira e civilização são duas coisas inconciliáveis. Elias (1994a, p. 23) nos mostra que o conceito de civilização pode englobar uma grande variedade de fatos, como tecnologia, tipos de maneiras, ciência, ideias religiosas e costumes. "Pode se referir ao tipo de habitações ou à maneira como homens e mulheres vivem juntos, à forma de punição determinada pelo sistema judiciário ou ao modo como são preparados os alimentos". Na verdade, qualquer coisa pode ser feita de forma civilizada ou incivilizada.

Sem dúvidas, a forma como nos comportamos à mesa e as regras de etiqueta que utilizamos para isso é parte do processo civilizador. No entanto, este diz respeito à consciência que o mundo ocidental tem de si mesmo e, portanto, apresenta também algo de excludente por se julgar superior a outras sociedades (ELIAS, 1994a).

Assim, tendemos a reprimir ou interditar nossos sentimentos por uma questão de comportamento. É pela etiqueta que apresentamos distinção social: diferenciamonos daqueles que não conhecem as regras para fazer parte de uma comunidade de pertencimento. É uma forma de dissolver as diferenças dentro de um grupo e, portanto, de gerar igualdade, mas que, como dito anteriormente, é uma igualdade excludente. É o caso, por exemplo, de Eugênio de Rastignac: ele frequenta os bailes da alta sociedade, veste-se e comporta-se como os demais, sendo visto como um primo da Sra. Béauseant e não como um morador da Casa Vauquer.

A Casa Vauquer, localizada em um bairro decadente e marginalizado de Paris, tinha durante os almoços e jantares o aspecto de uma refeição íntima. Os pensionistas, internos e externos, entram uns após os outros, trocando cumprimentos e, constantemente, gracejos: “Aqui está sua excelência o marquês de Rastignac, doutor em direito-torto - exclamou Bianchon, agarrando Eugênio pelo pescoço e apertando-o até quase sufocá-lo" (BALZAC, 2012, p. 77).

Bianchon não reprime sua fome: "Vamos todos para a mesa, depressa!" (BALZAC, 2012, p. 76); "Vamos à boia? — gritou Horácio Bianchon, um estudante 
de medicina muito ligado a Rastignac. - Meu estomagozinho já está lá nos calcanhares" (BALZAC, 2012, p. 77). E Rastignac serve-se abundantemente do carneiro e corta um pedaço de pão que a avarenta Sra. Vauquer mede com os olhos.

Enquanto prega-se que devemos ter conversas tranquilas e controle de nossos comportamentos, essas refeições cotidianas apresentam marcas de barulho, conflito e desordem, que se exacerbam quando o vinho de Bordéus começa a circular entre os comensais. Nesse momento "Ouviram-se risos ferozes, no meio dos quais se destacaram algumas imitações de diversas vozes de animais. Como o empregado do museu tivesse tido a ideia de reproduzir um pregão de Paris que tinha analogia com o mio do gato amoroso, imediatamente oito vozes berraram simultaneamente" (BALZAC, 2012, p. 214).

Estar junto e, portanto, comer junto, é afetar e ser afetado. “O 'contato' - a contiguidade, a fricção, o encontro e a colisão - é a modalidade fundamental do afeto" (NANCY, 2007, p. 51). Praticamos a comensalidade não como continuidade nem refletindo uma comunicação eficaz, mas sim na contrariedade e no conflito.

Perguntamo-nos, assim, se comer junto é conflituoso, por que estamos sempre nostálgicos em relação a essa prática que, diante de uma sociedade cada vez mais individualista, não realizamos com tanta frequência?

Rossi (2014, p. 121) considera essa nostalgia como um primitivismo que busca a volta à natureza e que não leva em conta o sofrimento envolvido na grande luta pela sobrevivência, quando as pessoas sofriam muito e morriam jovens. A natureza, longe de ser uma divindade intacta, é resultado da presença humana na Terra. Na maior parte da história, o homem conviveu e convive com o medo e a violência. Se por um lado as comidas de nossos antepassados eram mais naturais, genuínas e saborosas, por outro, desconsideramos a desnutrição, a falta de higiene e problemas de saúde decorrentes dela e o patriarcalismo que envolvia a produção e o consumo das refeições, em que o chefe da família era o provedor e para ele deveriam ir todas as regalias.

Essa ideia de uma comunidade perdida ou nostálgica associa-se à família, às civilizações primitivas ou tradicionais ou à ágape cristã, que nos remetem a uma ideia de harmonia e laços sociais resistentes que proporcionam a formação de uma unidade. No entanto, Nancy (2000, p. 23, tradução nossa) afirma que os que andam perdidos somos nós mesmos, "sobre quem o 'vínculo social' (as relações, a comunicação), nossa invenção, recai pesadamente como a rede de uma armadilha econômica, técnica, política, cultural", assim procuramos uma comensalidade formada em uma comunidade de união e harmonia que pensamos ter ficado no passado. 


\section{Considerações finais}

A literatura foge à regra, torna-se importante para pensarmos a alimentação como amor, prazer, solidariedade e afeto, mas também como algo que pode ser cruel e provocar a negação e a exclusão do outro.

No symposium grego, na cena romana ou nos cerimoniais feudais, a comida está presente em nosso imaginário e configura-se como elemento unificador em reuniões de iguais. Igualdade, comunhão e fraternidade rondam o nosso imaginário ao pensarmos no comer junto. A mesa é um espaço de prazer, mas também de poder. Desde a pré-história, com o domínio do fogo e da agricultura, é isso que o homem deseja.

Reunir os envolvidos em uma vitória militar da Antiguidade ou os monges da era medieval promove a formação de uma comunidade que nos remete a um ideal de segurança e fraternidade. No entanto, o espaço de igualdade provoca também separação e distinção.

Comer é poder, é pecado, é gula. Se por uma questão ética criamos a etiqueta, ela também surge como agente excludente que rejeita aqueles que não a seguem. Ela é uma marca de coletividade e civilização, como também são as regras que permeiam a refeição: horário das refeições, alimentos que são servidos em determinadas ocasiões, onde se come, com quem se come. É em meio à coletividade que podemos também expor nossas individualidades.

Em oposição à reunião de iguais, bem como a um individualismo, acreditamos ser de extrema importância pensarmos na hospitalidade e O Pai Goriot de Balzac (2012), nos permite esta reflexão. Quando a Sra. Vauquer aceita em seu estabelecimento qualquer um, ela se abre ao outro, ainda que com desconfiança e estranhamento. Ela nos mostra como é difícil lidar com a alteridade. O Outro, seja ele um estrangeiro de outra nacionalidade, a comida de um outro lugar, alguém com um hábito alimentar diferente: vegano, intolerante ao glúten ou à lactose, crudivorista etc. está sempre em relação de enfrentamento e é preciso saber lidar com isso.

\section{CoMmunity at THE TABLE: COMMENSALITY IN the novel Father Goriot by BaLzac}

ABSTRACT: Our objective is to understand commensality as a social phenomenon through the novel Father Goriot by Balzac, which constitutes our research corpus. The story takes place in a pension in a poor neighborhood in Paris, called Maison Vauquer. In this setting, the dining table appears as a background for eating habits, 
as well as disagreements and disharmony in the group and in the community. From there, the question of what constitutes this community can be raised. In order to reflect upon it, we will use the notions of unavowable community and inoperative community by Maurice Blanchot and Jean-Luc Nancy. These communities are not possible in communion, but in estrangement. Therefore, we are able to consider the table of Vauquer's pension as a place of both hostility and hospitality; with signs of the individual and the collective; and where conflicts and disorder prevail.

KEYWORDS: Community. Commensality. Balzac. Father Goriot.

\section{REFERÊNCIAS}

BALZAC, Honoré de. O pai Goriot. Tradução de Gomes da Silveira. In: BALZAC, Honoré de. A Comédia Humana: estudos de costumes: cenas da vida privada. 3 ed. São Paulo: Globo, 2012.

BALZAC, Honoré de. Tratados da vida moderna. Tradução de Leila de Aguiar Costa. São Paulo: Estação Liberdade, 2009.

BARTHES, Roland. O rumor da língua. Tradução de Mário Laranjeira. São Paulo: Brasiliense, 1988.

BLANCHOT, Maurice. A comunidade inconfessável. Tradução de Eclair Antonio Almeida Filho. Brasília: Editora UnB; São Paulo: Lumme Editor, 2013.

CORBEAU, Jean-Pierre. Rituels alimentaires et mutations sociales. Cahiers internationaux de sociologie, p. 101-120, 1992.

DERRIDA, Jacques; DUFOURMANTELLE, Anne. Anne Dufourmantelle convida Jacques Derrida a falar da hospitalidade. Tradução de Antonio Romane. Escuta, 2003.

DOUGLAS, Mary. Pureza e perigo. Tradução de Sónia Pereira da Silva. Lisboa: Edições $70 ; 1990$.

DURKHEIM, Émile. As regras do método sociológico. Tradução de Paulo Neves. São Paulo: Martins Fontes, 2007.

ELIAS, Nobert. A sociedade dos indivíduos. Tradução de Vera Ribeiro. Rio de Janeiro: Zahar, 1994a.

ELIAS, Norbert. O processo civilizador. Tradução de Ruy Jungmann. Rio de Janeiro: Jorge Zahar, 1994b. (Vol. 1). 
FOUCAULT, Michel. Microfísica do poder. Tradução de Roberto Machado. 4. ed. Rio de Janeiro: Edições Graal, 1984.

GOZLAN, León. Balzac Chez lui: souvenirs des Jardies. 12.ed. Michel Lévy Frères: Paris, 1863.

GRASSI, Marie-Claire. Hospedaria: do albergue ao hotel. In: MONTANDON, Alain. O livro da Hospitalidade: Acolhida do estrangeiro na História e nas culturas. Tradução de Marcos Bagno e Lea Zylberlicht. São Paulo: Editora Senac São Paulo, 2011.

GUILLAUME, Pierre. Hospital: entre o técnico e o humano. In: MONTANDON, Alain. O livro da Hospitalidade: Acolhida do estrangeiro na História e nas culturas. Tradução de Marcos Bagno e Lea Zylberlicht. São Paulo: Editora Senac São Paulo, 2011.

HOUAISS, A. Dicionário eletrônico Houaiss da língua portuguesa 3.0. Rio de Janeiro: Objetiva, 2009.

LANDINI, José Carlos. Do animal ao humano: uma leitura psicodramática. Editora Ágora, 1998.

LEPENIES, Wolf. As Três Culturas. Tradução de Maria Clara Ceseato. São Paulo: Edusp, 1996.

MONTANARI, Massimo. Comida como cultura. Tradução de Letícia Martins de Andrade. São Paulo: Senac São Paulo, 2008.

MAYRING, Philipp. Qualitative inhaltsanalyse: Grundlagen und Techniken. Basel: Beltz, 1983.

MONTANDON, Alain. O livro da Hospitalidade: Acolhida do estrangeiro na História e nas culturas. Tradução de Marcos Bagno e Lea Zylberlicht. São Paulo: Editora Senac São Paulo, 2011.

MONTEILHET, Véronique. HONORÉ DE BALZAC. Sociologia da vida parisiense. In: MONTANDON, Alain. O livro da Hospitalidade: Acolhida do estrangeiro na História e nas culturas. Tradução de Marcos Bagno e Lea Zylberlicht. São Paulo: Editora Senac São Paulo, 2011.

MUHLSTEIN, Anka. Garçon, un cent d'huîtres!: Balzac et la table. Paris: Odile Jacob, 2010.

NANCY, Jean-Luc. La comunidad enfrentada. Tradução de Juan Manuel Garrido. Buenos Aires: La Cebra, 2007.

NANCY, Jean-Luc. La comunidad inoperante. Tradução de Juan Manuel Garrido Wainer. Santiago de Chile: Escuela de Filosofía Universidad ARCIS, 2000. 
PERLÉS, Catherine. Les origines de la cuisine - l'acte alimentaire dans l'histoire de l'homme. Communications, n. 31, 1979.

ROSSI, Paolo. Comer: necessidade, desejo e obsessão. Tradução de Ivan Esperança Rocha. São Paulo: Unesp, 2014.

SIMMEL, Georg. Sociologia da refeição. Estudos Históricos, Rio de Janeiro, n. 33, jan-jun, p. 159-166, 2004.

SLOTERDIJK, Peter. Esferas III: Espumas. Tradução de Isidoro Reguera. Madrid: Siruela, 2009.

Recebido em 23/01/2018.

Aprovado em 22/04/2018. 
